\title{
Stability in subtropical forests: The role of tree species diversity, stand structure, environmental and socio-economic conditions
}

\author{
Shuai Ouyang ${ }^{1,2}$ (D) | Wenhua Xiang ${ }^{1,2}$ (D) | Mengmeng Gou ${ }^{3}$ | Liang Chen ${ }^{1,2}$ | \\ Pifeng Lei, ${ }^{1,2}$ | Wenfa Xiao ${ }^{3}$ | Xiangwen Deng ${ }^{1,2}$ | Lixiong Zeng ${ }^{3}$ | Jiangrong Li ${ }^{4}$ | \\ Tao Zhang $^{5}$ (D) | Changhui Peng ${ }^{6,7}$ | David I. Forrester ${ }^{8}$
}

${ }^{1}$ Faculty of Life Science and Technology, Central South University of Forestry and Technology, Changsha, Hunan, China

${ }^{2}$ Huitong National Station for Scientific Observation and Research of Chinese Fir Plantation Ecosystems in Hunan Province, Huitong, Hunan, China

${ }^{3}$ Key Laboratory of Forest Ecology and Environment, State Forestry and Grassland Administration, Research Institute of Forest Ecology, Environment and Protection, Chinese Academy of Forestry, Beijing, China

${ }^{4}$ Tibet Agricultural and Animal Husbandry University, Linzhi, Tibet, China

${ }^{5}$ Department of Biology, University of Florida, Gainesville, FL, USA

${ }^{6}$ College of Resources and Environmental Science, Hunan Normal University,

Changsha, Hunan, China

${ }^{7}$ Institute of Environment Sciences, Department of Biological Sciences,

University of Quebec at Montreal, Montreal, Quebec, Canada

${ }^{8}$ Swiss Federal Institute of Forest, Snow and Landscape Research WSL, Birmensdorf, Switzerland

Correspondence

Wenhua Xiang, Faculty of Life Science and Technology, Central South University of Forestry and Technology, No. 498 Southern Shaoshan Road, Changsha 410004, Hunan, China.

Email:xiangwh2005@163.com

Funding information

National Key Research and Development Program of China, Grant/Award Number: 2016YFD0600202; National Natural Science Foundation of China, Grant/Award Number: 31700636

Editor: Carsten Meyer

\begin{abstract}
Aim: Tree species diversity can increase the stability of ecosystem productivity by increasing mean productivity and/or reducing the standard deviation in productivity. However, stand structure, environmental and socio-economic conditions influence plant diversity and might strongly influence the relationships between diversity and stability in natural forest communities. The relative importance of these factors for community stability remains poorly understood in complex (species-rich) subtropical forests.
\end{abstract}

Location: Subtropical area of southern China.

Time period: 1999-2014.

Major taxa studied: Forest trees.

Methods: We conducted bivariate analyses to examine the mechanisms (overyielding and species asynchrony) underlying the effects of diversity on stability. Multiple regression models were then used to determine the relative importance of tree species diversity, stand structure, socio-economic factors and environmental conditions on stability. Structural equation modelling was used to disentangle how these variables directly and/or indirectly affect forest stability.

Results: Tree species richness exerted a positive effect on stability through overyielding and species asynchrony, and this effect was stronger in mountainous forests than in hilly forests. Species richness positively affected the mean productivity, whereas species asynchrony negatively affected the variability in productivity, hence increasing forest stability. Structural diversity also had a positive effect, whereas population density had a negative effect on stability. Precipitation variability and slope mainly had indirect influences on stability through their effects on tree species richness.

Main conclusions: Overall, tree species diversity governed stability; however, stand structure, socio-economic conditions and environmental conditions also played an important role in shaping stability in these forests. Our work highlights the importance of regulating stand structure and socio-economic factors in forest management and biodiversity conservation, to maintain and enhance their stability to 
provide ecosystem services in the face of unprecedented anthropogenic activities and global climate change.

\section{KEYWORDS}

biodiversity, community stability, ecosystem functioning, environmental conditions, population density, species asynchrony, stand attributes

\section{1 | INTRODUCTION}

Forest ecosystems not only provide the primary habitats for a wide range of species, but are also essential for the provision of a diverse range of ecosystem services to human society (Ferreira et al., 2018; Isbell et al., 2017). Ecosystem processes change through time in response to environmental fluctuations and disturbances (GarcíaPalacios et al., 2018; Polley \& Wilsey, 2018). In this context, the stability of forest productivity (hereafter "stability") is a management goal to sustain ecosystem services for an expanding human population and in the face of global change (Millar \& Stephenson, 2015; Polley \& Wilsey, 2018). A prerequisite to stabilizing productivity is an improved understanding of how biological attributes of ecosystems interact with environmental fluctuations to affect temporal variability in plant growth (Polley \& Wilsey, 2018).

There is mounting evidence that biodiversity enhances forest stability and ecosystem functioning and services (e.g., Hautier et al., 2014; Isbell et al., 2015; Jucker et al., 2014; Yuan et al., 2019). The stability reflects how much community biomass fluctuates through time, often annually, which can be defined as the ratio between mean productivity $(\mu)$ and its variation $(\sigma$, the SD of productivity) (Jucker et al., 2014; Wang \& Loreau, 2016). Overyielding and species asynchrony are the two main mechanisms proposed to explain the effects of diversity on the temporal stability of ecosystem processes (Hector et al., 2010). Overyielding mathematically increases ecosystem stability by increasing $\mu$ relative to $\sigma$ (Hector et al., 2010; Lehman \& Tilman, 2000). Species synchrony is related to the temporal complementarity among species, which could generate a stabilizing influence by reducing $\sigma$ (Loreau \& de Mazancourt, 2013). Greater plant species richness has been shown to result in a greater stability of plant community productivity over many years in grasslands (Hautier et al., 2014; Isbell et al., 2015; Wang, Cadotte, et al., 2019) and dryland ecosystems (García-Palacios et al., 2018). For forest ecosystems, however, most studies to date were conducted in comparatively species-poor forest ecosystems, such as European temperate forests (del Río et al., 2017; Jucker et al., 2014), Canadian boreal forests (Aussenac et al., 2019) and tropical experimental tree plantations (Schnabel et al., 2019). Tree plantation experiments allow an examination of the underlying mechanisms, but their results are difficult to extrapolate to "real-world" ecosystems that are influenced by human activities. In contrast, causal inference can be more difficult using large-scale inventory datasets of naturally regenerated forests, but these can be used to study the impacts of environmental gradients and socio-economic factors on the relationship between species diversity and stability.
The effects of species diversity on stand stability have been extensively reported, whereas structural diversity has received less investigation (Forrester, 2019; Lei et al., 2009; Liang et al., 2007; Soares et al., 2016). Metrics of structural diversity, such as the Gini coefficient (Weiner \& Solbrig, 1984), standard deviation (SD) and coefficient of variation (CV) of tree diameters (Schnabel et al., 2019; Soares et al., 2016; Zhang \& Chen, 2015), have been found to affect stand productivity (Soares et al., 2016; Zhang \& Chen, 2015).

Beyond species diversity and structural diversity, other environmental factors (such as local climate and topography) can also influence forest stability directly or indirectly via their effects on species richness and stand structural attributes (del Río et al., 2017; Jucker et al., 2014, 2016; Poorter et al., 2017). Precipitation and interannual variability in precipitation influence community stability by altering community composition and species richness (García-Palacios et al., 2018; Isbell et al., 2015; Mazzochini et al., 2019). Topography has proved to be a good predictor of plant resource availability (Guo et al., 2017) and thus to be a key driver for determining tree species diversity, stand structure and productivity (Bohlman et al., 2008; Guo et al., 2014) and further affecting the relationship between diversity and forest productivity (Poorter et al., 2017; Takyu et al., 2002). Moreover, other studies have found that tree cover (a proxy for productivity) is affected by topography because steep terrain is less accessible to human activities (Belote, 2018; Nüchel et al., 2019). Therefore, it is important to understand how variability in environmental factors influences stability.

Increasing human disturbances and pressures (e.g., economic development, urban expansions and human population density) have caused widespread forest fragmentation and degradation [Chazdon et al., 2017; Ferreira et al., 2018; Food and Agriculture Organization (FAO), 2015; Gonzalez et al., 2020]. The frequency and severity of these processes are likely to increase (Isbell et al., 2015; Jactel et al., 2017), and there might be new combinations of disturbances and pressures as a result of global change and other anthropogenic influences (Millar \& Stephenson, 2015). These processes could affect vegetation composition, diversity and growth, and thereby reduce resistance to natural or anthropogenic disturbance (Newbold et al., 2015; van der Plas et al., 2016) and also affect forest stability (Greve et al., 2011; Messier et al., 2019). Rapid human population density growth, accelerated economic development and drastic land-use change have been the main sources of human disturbances and pressures that have resulted in biodiversity loss (Chen et al., 2018; Huang et al., 2019; Martínez-Ramos et al., 2016; Quan et al., 2011). Previous studies have also shown that socio-economic factors (e.g., drastic increases in human population density) have 
had negative effects on forest growth owing to the greater risk of forest destruction to support the development of social and economic systems (Nüchel et al., 2019; Wen et al., 2017). Moreover, it is worth noting that the relationship between biomass production and diversity is not direct, but is also mediated by human management and human population density (Messier et al., 2019; Schulze et al., 2018). However, little is known about the influence of these disturbance-mediated changes on the relationship between stability and diversity in forests. Therefore, understanding how socio-economic factors influence this relationship should be considered in further research.

Subtropical forests are an important hotspot of tree species richness, often in heterogeneous environments (Liu et al., 2018; Xiang et al., 2016). These forests have a high capacity for carbon (C) storage and have the potential to sequester huge amounts of $C$ in the future (Liu et al., 2018; Ouyang et al., 2019). Nevertheless, anthropogenic disturbances (e.g., logging, agriculture and urban expansion) have resulted in drastic changes in ecological conditions that have caused biodiversity loss and reduced the capacity of these forests to maintain important ecosystem functions and services (Liu et al., 2018). The complex interactions of species diversity, stand structure, environment and human influence on stability have not yet been examined, although an understanding of these processes is crucial for designing biodiversity conservation and effective management strategies.

The areas where forests are distributed in southern China can be classified as mountainous areas and hilly areas. Forests in mountainous areas are located at high elevations and on steep slopes, where forests are difficult to access for harvest and the main management objective is nature conservation; thus, these forests have very low management intensity. In contrast, forests in hilly areas are located on gentler topography (low elevations and less steep slopes); hence, they experience a higher management intensity. We hypothesize that forests in mountainous areas will exhibit a stronger relationship between diversity and forest stability, owing to the complex topography and lower level of human activities than in hilly areas. In order to study the effects of such factors on stability, the statistical replication of biomass or productivity should be sufficiently large (e.g. Jucker et al., 2014; del Rio et al., 2017). Large-scale estimates of biomass have been derived successfully from national forest inventory (NFI) data and have provided important insights into large-scale forest biomass stock and productivity dynamics (Fang et al., 2014; Ouyang et al., 2019; Pan et al., 2011).

In this study, we analysed a large dataset including national forest inventories from 1999 to 2014 across Hunan Province, China, to address three major questions:

1. Is stability significantly associated with tree species diversity in subtropical forests?

2. What are the effects of overyielding and species asynchrony on stability of subtropical forests?

3. What are the main driving factors determining stability of subtropical forests?
In order to answer these questions, we investigated a key suite of species diversity, stand structure, environmental conditions and socio-economic variables that we hypothesize might modulate forest stability and its two components ( $\mu$ and $\sigma$ of productivity). Specifically, we hypothesize that: (a) diversity is positively correlated with stability after controlling for the effects of stand structure, environmental factors and socio-economic factors, and the positive effect of diversity on stability in mountainous areas is stronger than that in hilly areas because forests in hilly areas experience more intense human impacts; (b) overyielding affects stability more strongly than species asynchrony in subtropical forests, because relatively slow changes in species composition of forests might limit the importance of species asynchrony as a promoter of stability (del Río et al., 2017; Jucker et al., 2014; Yu et al., 2020); and (c) environmental and socio-economic factors also exert direct and indirect effects on stability via their effects on species and stand structure.

\section{2 | MATERIALS AND METHODS}

\section{1 | Study area}

The study was conducted in Hunan Province (latitude $108^{\circ} 47^{\prime}$ $114^{\circ} 15^{\prime} \mathrm{E}$, longitude $24^{\circ} 38^{\prime}-30^{\circ} 08^{\prime} \mathrm{N}$ ), situated in the mid-subtropical area of China (Figure 1). Hunan Province is located in the transition zone from the Yunnan-Guizhou plateau to the lower mountains and hills on the southern side of the Yangtze River and has an elevation between 21 and 2,122 $\mathrm{m}$ a.s.l. The study area has a typical humid mid-subtropical monsoon. The mean annual air temperature is $16-18^{\circ} \mathrm{C}$. The mean precipitation is c. $1200-1700 \mathrm{~mm}$, occurring primarily between April and October (Huang et al., 2014). The soils are red-yellow podzolic soils, which developed mostly from slate and shale parent material, and are classified as Plinthudults, according to the U.S. Soil Taxonomy. The climax vegetation of the region is subtropical evergreen broadleaved forest. Owing to anthropogenic disturbances in the 1960s-1970s, most natural forests were converted into plantations (Qi, 1990). Since the late 1980s, the Chinese government has implemented afforestation and natural forest restoration projects, meaning that most forests have naturally generated and become secondary forests. The forest areas of Hunan Province have increased rapidly from $43.5 \%$ of its total land area in the 1980 s to $55.9 \%$ in the 2010 s. Most forests are mixtures of coniferous, deciduous broadleaved and evergreen broadleaved species (Song, 2013; Xiang et al., 2016).

\section{2 | Forest inventory and data collection}

The stand data were acquired from permanent sample plots (25.82 $\mathrm{m} \times 25.82 \mathrm{~m}$, according to the protocols of the National Forest Inventory standards issued by the Chinese Ministry of Forestry) located across Hunan Province (Figure 1) from 1999 to 2014, which were surveyed in the Fourth to Seventh National 
$109^{\circ} 0^{\prime} 0^{\prime \prime} \mathrm{E} \quad 110^{\circ} 0^{\prime} 0^{\prime \prime} \mathrm{E} \quad 111^{\circ} 0^{\prime} 0^{\prime \prime} \mathrm{E} \quad 112^{\circ} 0^{\prime} 0^{\prime \prime} \mathrm{E} \quad 113^{\circ} 0^{\prime} 0^{\prime \prime} \mathrm{E} \quad 114^{\circ} 0^{\prime} 0^{\prime \prime} \mathrm{E}$
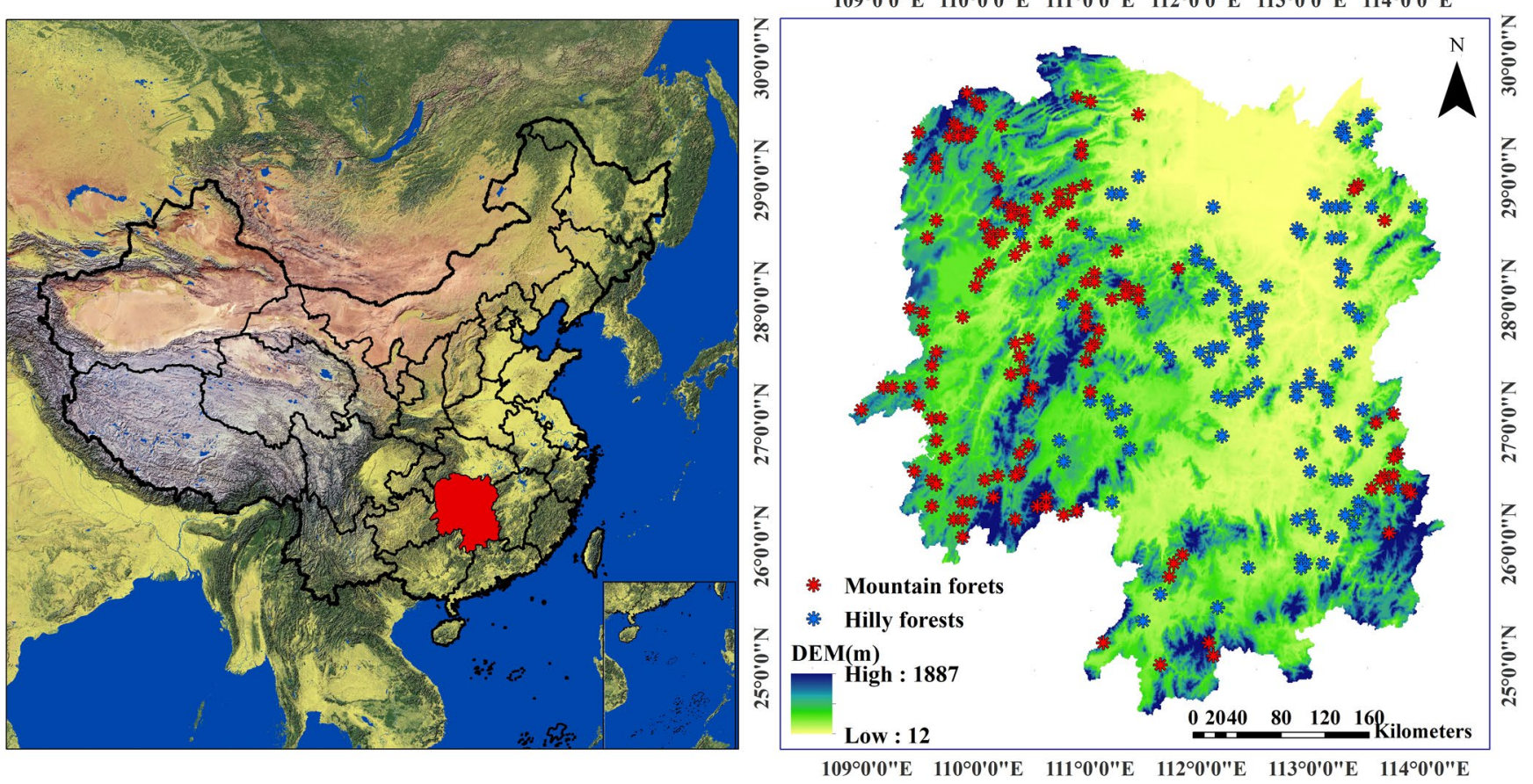

FIGURE 1 Spatial distribution of the forest plots in southern China. Blue dots indicate forests in hilly areas, and red dots indicate forests in mountainous areas [Colour figure can be viewed at wileyonlinelibrary.com]

Forest Inventories of China (1999, 2004, 2009 and 2014). Our study sites represent a typical topography and intensity of anthropogenic disturbance, and we grouped them into two disturbance levels relevant to topographic and socio-economic factors: mountainous forests $(n=137)$ and hilly forests $(n=105)$ (Figure 1$)$. Within each plot, geographical location (latitude and longitude) and topographical variables (slope, elevation and slope position) were measured. All individual trees $\geq 5 \mathrm{~cm}$ diameter at breast height (d.b.h., $1.3 \mathrm{~m}$ ) were recorded and identified to the species level.

\section{3 | Calculations of productivity and community temporal stability}

All individuals with a d.b.h. $\geq 5 \mathrm{~cm}$ were used in the analysis. After the total stock volume for each plot was calculated, the total biomass was estimated using the biomass expansion factor method, which is an accurate method for estimation of forest biomass at large scales (Fang et al., 2014). The forest productivity was then determined as biomass increments between two inventories (Ouyang et al., 2019).

The community temporal stability of productivity within each plot was quantified as (Jucker et al., 2014; Wang \& Loreau, 2016):

$$
\text { Stability }=\frac{\mu}{\sigma}
$$

where $\mu$ and $\sigma$ are the mean and the SD of the productivity of the inventory data with four repetitions.

\subsection{Species synchrony and overyielding}

Species asynchrony was calculated for each plot as (Loreau \& de Mazancourt, 2013):

$$
\text { Species asynchrony }=1-\frac{\delta^{2}}{\left(\sum_{i=1}^{N} \delta i\right)^{2}}
$$

where $\delta$ is the variance of community productivity, and $\delta_{i}$ is the $S D$ of productivity of species $i$ in a community with $N$ species. Species asynchrony reflects how the productivity of multiple species differs over the time. We performed linear regressions between species asynchrony and stability, in addition to its two components ( $\mu$ and $\sigma$ ). A positive relationship between species richness and mean productivity indicates that effects of overyielding contribute to ecosystem stability (Hector et al., 2010; Jucker et al., 2014). We expect overyielding to increase mean productivity, and we expect species asynchrony to decrease the temporal variation in productivity.

\subsection{Species diversity and stand structure}

We used species and structural diversity metrics to improve our understanding of the processes that drive stability, because previous studies have shown that these metrics can be correlated strongly with forest productivity (Dănescu et al., 2016; Schnabel et al., 2019). Species diversity was quantified as species richness (number of tree species within a plot). Stand structure was quantified by tree size (d.b.h.) and structural diversity. Using the method suggested by 
TABLE 1 Biotic and abiotic variables used in the analysis and their sources

\begin{tabular}{|c|c|c|c|}
\hline Variable & Definition & Unit & Source \\
\hline Climatic & & & $\begin{array}{l}\text { China Meteorological Data Sharing } \\
\text { Service System (http://data.cma.cn/) }\end{array}$ \\
\hline MAT & $\begin{array}{l}\text { Mean annual } \\
\text { temperature }\end{array}$ & ${ }^{\circ} \mathrm{C}$ & \\
\hline$S D$ of MAT & $\begin{array}{l}\text { Standard deviation } \\
\text { of mean annual } \\
\text { temperature }\end{array}$ & & \\
\hline MAP & $\begin{array}{l}\text { Mean annual } \\
\text { precipitation }\end{array}$ & $\mathrm{mm}$ & \\
\hline$S D$ of MAP & $\begin{array}{l}\text { Standard deviation } \\
\text { of mean annual } \\
\text { precipitation }\end{array}$ & & \\
\hline \multicolumn{4}{|l|}{ Topographic } \\
\hline Slope & Surface gradient & $\circ$ & \\
\hline Elevation & Elevation & $\mathrm{m}$ & \\
\hline $\begin{array}{l}\text { Socio- } \\
\text { economic }\end{array}$ & & & RESDC, http://www.resdc.cn \\
\hline GDP & $\begin{array}{l}\text { Gross domestic } \\
\text { product per square } \\
\text { kilometre }\end{array}$ & $\mathrm{RMB} / \mathrm{km}^{2}$ & \\
\hline $\begin{array}{l}\text { Population } \\
\text { density }\end{array}$ & $\begin{array}{l}\text { Human population } \\
\text { density per square } \\
\text { kilometre }\end{array}$ & $\begin{array}{l}\text { number/ } \\
\mathrm{km}^{2}\end{array}$ & \\
\hline \multicolumn{4}{|l|}{$\begin{array}{l}\text { Species } \\
\text { diversity }\end{array}$} \\
\hline $\begin{array}{l}\text { Species } \\
\text { richness }\end{array}$ & Species in a plot & $\begin{array}{l}\text { number/ } \\
\text { plot }\end{array}$ & \\
\hline \multicolumn{4}{|l|}{$\begin{array}{l}\text { Stand } \\
\text { structure }\end{array}$} \\
\hline d.b.h. & $\begin{array}{l}\text { Diameter at breast } \\
\text { height }\end{array}$ & $\mathrm{cm}$ & \\
\hline$S D$ of d.b.h. & $\begin{array}{l}\text { Standard deviation } \\
\text { of d.b.h. }\end{array}$ & & \\
\hline CV of d.b.h. & $\begin{array}{l}\text { Coefficient of } \\
\text { variation of d.b.h. }\end{array}$ & & \\
\hline $\begin{array}{l}\text { Gini CV of } \\
\text { d.b.h. }\end{array}$ & $\begin{array}{l}\text { Gini coefficient of } \\
\text { d.b.h. }\end{array}$ & & \\
\hline
\end{tabular}

Schnabel et al. (2019), three metrics of forest structural diversity (SD of d.b.h., CV of d.b.h. and Gini CV of d.b.h.) were calculated to quantify the diversity of diameter.

\subsection{Environmental variables}

We used elevation and slope as topographical factors that can potentially influence forest productivity. For each location, we gathered annual climatic data (mean air temperature and precipitation) of the same period (1999-2014) from the meteorological stations across Hunan Province (http://data.cma.cn/). We chose four climatic variables, including mean annual temperature (MAT; in degrees Celsius), mean annual precipitation (MAP; in millimetres), interannual variability in precipitation (SD of MAP) and interannual variability in temperature (SD of MAT). Previous studies have shown that these variables represent the mean annual levels and variability of precipitation and temperature (García-Palacios et al., 2018; Holmgren et al., 2013) and that plant growth is likely to be affected by these variables (García-Palacios et al., 2018; Hutchison et al., 2014; Zhao and Running, 2010).

\section{7 | Socio-economic data}

Both human population density and gross domestic product (GDP) were used as variables to represent socio-economic activities. These two datasets ( $1 \mathrm{~km}$ resolution) were obtained from the Data Center for Resources and Environmental Sciences, Chinese Academy of Sciences (RESDC; http://www.resdc.cn; Xu, 2017a, 


\begin{tabular}{|lllll}
\hline Response & Predictor & Slope (SE) & $R^{2}$ & $\begin{array}{l}p \text { - } \\
\text { value }\end{array}$ \\
\hline Stability & Species richness & $0.431(0.058)$ & 0.186 & $<.001$ \\
\hline Mean productivity & Species asynchrony & $0.329(0.061)$ & 0.108 & $<.001$ \\
\hline Productivity variability & Species richness & $0.330(0.061)$ & 0.109 & $<.001$ \\
\hline Species asynchrony & Species asynchrony & $0.758(0.064)$ & 0.006 & .240 \\
\hline & Species richness & $-0.071(0.064)$ & 0.005 & .273 \\
\hline
\end{tabular}

TABLE 2 Model outputs of the linear regression testing of hypothesized drivers of stability 2017b). We calculated the mean values of population density and GDP between the 2000 and 2014 in our analysis to represent their effects on stability.

\subsection{Statistical analysis}

All variables used in this study are listed in Table 1. Linear regression analyses were used to evaluate the effects of species richness and species asynchrony on stability. One-way ANOVA, followed by the least significant difference (LSD), was used to test the differences in stability between the two areas (hilly and mountainous). Ordinary least squares regression and testing whether forest areas influenced the regressions were computed using the R package "smatr" v.3.4 (Warton et al., 2012). The coefficient of determination $\left(R^{2}\right)$, the $95 \%$ confidence intervals for the slopes and the intercepts of the regression between species richness and stability were determined.

Multiple regression models were used to examine the effects of diversity on stability and on its two components ( $\mu$ and $\sigma$ of productivity), in addition to those of covarying stand structural, socio-economic and environmental factors. All variables were standardized before conducting the multiple regression analysis. To remove the multicollinear variables (Supporting Information Figure S1), we included predictor variables in the models only when the variance inflation factor (VIF) was less than five (Uriarte et al., 2012). The VIF was calculated using the R package "car" (Fox et al., 2017). Consequently, the full model included four climatic variables (MAP, MAT, temperature variability and precipitation variability), two topographical variables (elevation and slope), two forest structure variables (tree d.b.h. and SD of d.b.h.), two socio-economic variables (GDP and population density), one forest type (i.e., hilly and mountain forests) and one diversity variable (species richness). The best model was selected using the corrected Akaike information criterion (AICC) by considering the lowest AICc and number of predictor variables (Bartoń, 2016; Burnham \& Anderson, 2002). This analysis was conducted using the dredge () function in the R package "MuMIn" (Bartoń, 2016).

Structural equation models were used to determine the direct and indirect effects of the above-mentioned driving factors on stability and its two components (mean and SD of productivity). We formulated a hypothetical causal model (Supporting
Information Figure S2), based on a priori knowledge, in two steps. Firstly, we divided stability into two components (mean and SD of productivity) and included direct paths from species richness and species asynchrony to the two components, which represent the underlying mechanisms of stability (Craven et al., 2018; Loreau $\&$ Hector, 2001). Secondly, we included indirect paths from climate (García-Palacios et al., 2018; Mazzochini et al., 2019), slope (Nüchel et al., 2019; Zhang et al., 2019) and population density (Chen et al., 2018; Schulze et al., 2018) to stability because these factors could affect the forest stability via species and structural diversity (Supporting Information Table S1). We parameterized our structural equation model and tested its goodness-of-fit using the goodness-of-fit index (GFI), chi-square test and standardized root mean square residual (SRMR). Requirements for an acceptable model included an insignificant chi-square test statistic with $p$ value $>.05$, GFI values and SRMR $>0.95$ and $<0.08$, respectively (Grace et al., 2016). The structural equation model was performed using the R package "lavaan" (Rosseel, 2012). All the statistical analyses were implemented in R v.3.4.1 (R Core Team, 2019).

\section{3 | RESULTS}

\section{1 | Effects of tree species diversity on stability}

Species richness was positively associated with forest stability (Table $2 ; R^{2}=0.186 ; p<.001$ ). Species asynchrony was also positively associated with stability (Table $2 ; R^{2}=0.108 ; p<.001$ ), and species richness was positively correlated with species asynchrony (Table $2 ; R^{2}=0.354 ; p<.001$ ). Species asynchrony was negatively associated with variability in productivity (Table $2 ; R^{2}=0.04$; $p=.004)$. All these relationships suggest that diversity promotes ecosystem stability through the effects of both overyielding and species asynchrony.

There were also significant positive relationships between species diversity and stability in both hilly and mountainous forests ( $p<.001$; Supporting Information Figure S3). However, the relationships differed significantly between topographical types $\left(F_{1,240}=45.0, p<.001\right)$, with higher stability in mountainous areas $\left(R^{2}=0.21, p<.001\right)$ than in hilly areas $\left(R^{2}=0.10, p<.001\right.$; Supporting Information Table S2). 


\section{2 | Drivers of forest stability and its components}

The multiple regression models accounted for $49.7 \%$ of the variation in forest stability (Figure 2). Among the environmental variables, slope had a significantly positive effect and precipitation variability a significantly negative effect on stability. In terms of biotic variables, stand structural diversity and species richness had strong positive effects on stability, followed by tree size and species asynchrony (Figure 2a).

When disentangling stability into two components of stability, species richness had a strong positive effect on mean productivity, followed closely by MAP, slope, tree d.b.h. and structural diversity, whereas population density and precipitation variability had strong negative effects on mean productivity (Figure $2 b$ ). Species richness and precipitation variability had significantly positive effects on productivity variability, whereas species asynchrony and structural diversity had significantly negative effects on productivity variability (Figure 2c).

\subsection{The direct and indirect effects of main drivers on stability and its two components}

The structural equation model provided a good fit to the data and accounted for $44.2 \%$ of the variation in stability (Figure 3a). Structural diversity, species richness, species asynchrony and slope had positive effects on stability, whereas precipitation variability and population density had negative effects on stability (Figure 3a).

A separate structural equation model that included the two components of stability (mean productivity and productivity variability) showed that species asynchrony increased stability by reducing the productivity variability (standardized path coefficient $=-0.25$ ). Species richness promoted stability by a faster increase in mean productivity (standardized path coefficient $=0.28$ ) than productivity variability (standardized path coefficient $=0.17$ ) (Figure $3 b$ ). Species richness also had a positive indirect effect via species asynchrony (indirect effect $=-0.12$ ). Structural diversity promoted ecosystem stability by increasing mean productivity (standardized path coefficient $=0.16$ ) and reducing productivity variability (standardized path coefficient $=-0.18$ ) (Figure $3 b$ )

Precipitation variability decreased stability by directly reducing mean productivity (standardized path coefficient $=-0.13$ ) and via species richness (indirect effect $=-0.04$ ) and directly increased productivity variability (standardized path coefficient $=0.17$ ) (Figure 3b). Population density decreased stability by decreasing mean productivity directly (standardized path coefficient $=-0.30$ ) and indirectly via species richness (indirect effect $=-0.05$ ), and indirectly increased productivity variability via species diversity (indirect effect $=-0.03$ ). Slope not only increased mean productivity directly (standardized path coefficient $=0.12$ ) and indirectly via species richness (indirect effect $=0.08$ ), but also indirectly increased productivity variability via species richness (indirect effect $=0.05$ ) (a)

Forest stability

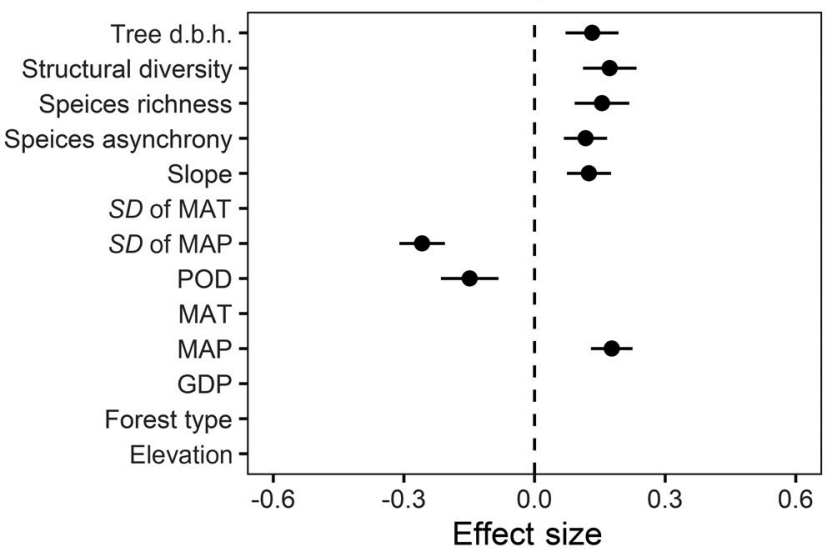

(b)

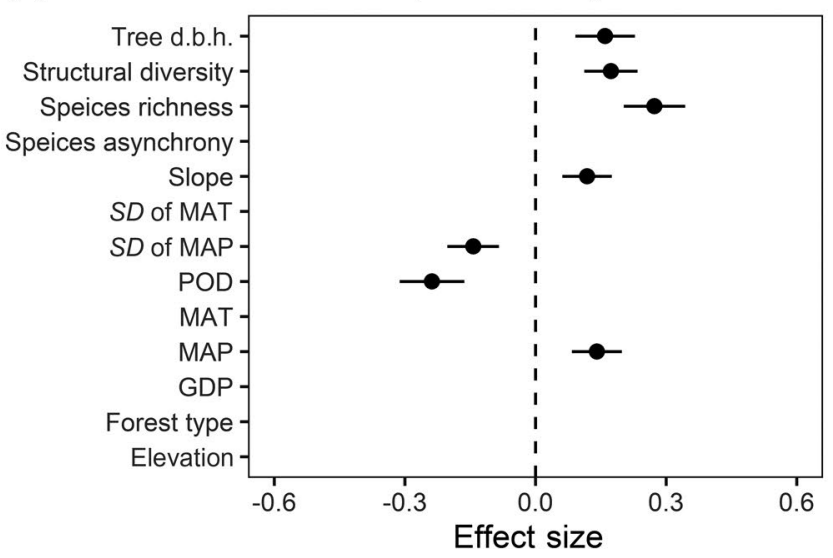

(c) Productivity variability

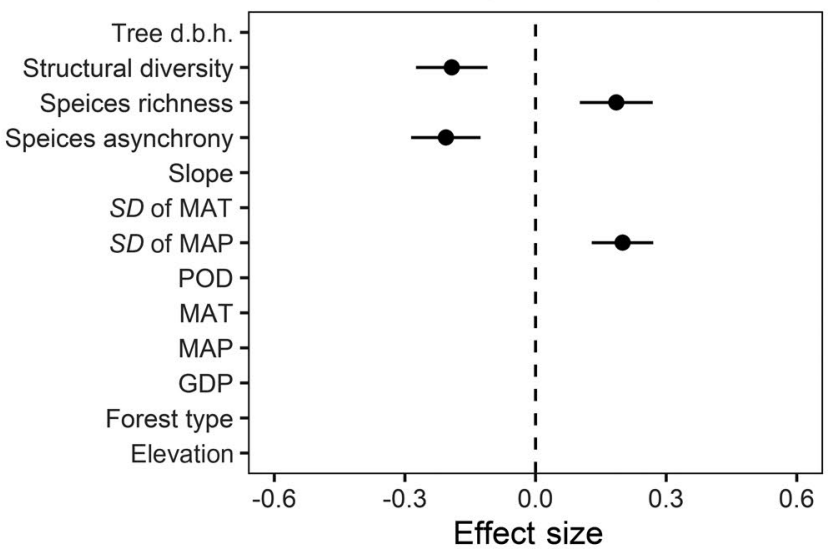

FIGURE 2 Effect of the predictor variables on (a) forest stability and its two components, namely (b) mean productivity and (c) productivity variability, from multiple regression models. Each variable was standardized, and their effect sizes (circles) were compared to determine differences in the strength of predictor variables. Filled circles indicate significant effects $(p<.05)$, and means $\pm 1 S E$ are shown. Note that the terms not included in the best-fitting model are left blank. Variables are described in Table 1

(Figure 3b). Given that the positive effect of slope on mean productivity was greater in magnitude than that of productivity variability, the total effect on stability was positive (Figure $3 b$ ). 
(a)

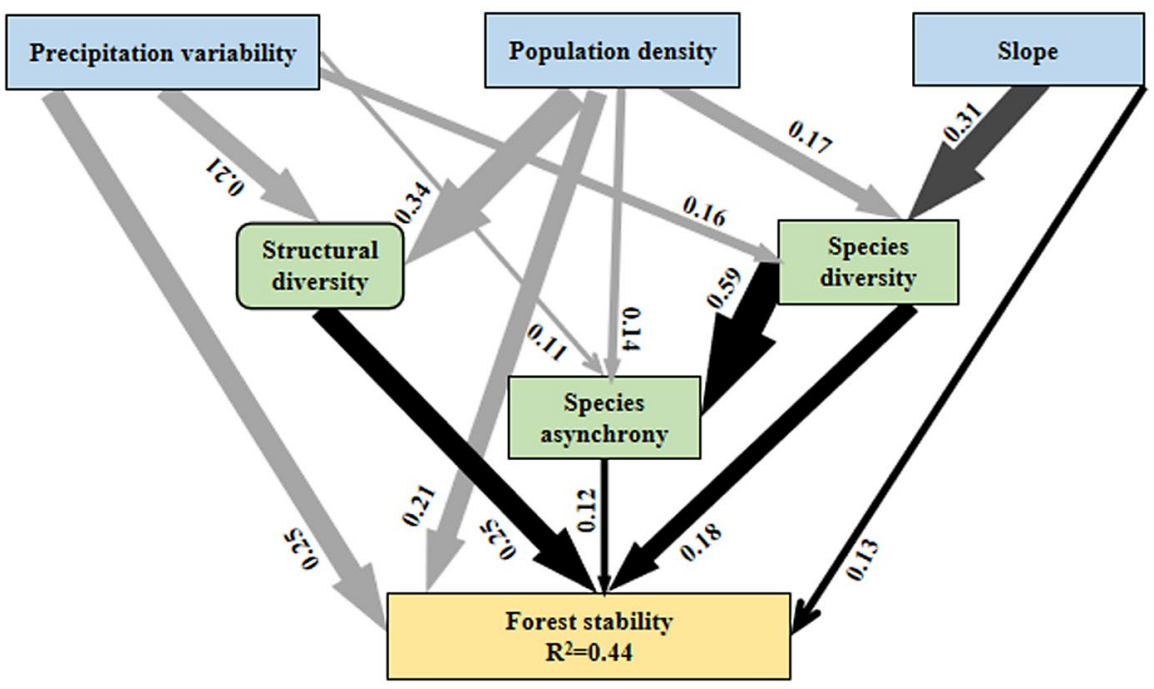

FIGURE 3 Structural equation model relating (a) forest stability and (b) its two components, mean productivity and productivity variability, to climate, slope, population density, species diversity, structural diversity and species asynchrony in subtropical forests. The coefficients are standardized prediction coefficients for each causal path. Continuous lines represent significant paths $(p \leq .05)$ (black = positive; grey $=$ negative). Non-significant paths $(p>.05)$ are not shown. The thickness of the solid arrows reflects the magnitude of the standardized prediction coefficients. $R^{2}$ denotes the proportion of variance explained [Colour figure can be viewed at wileyonlinelibrary.com]

(b)

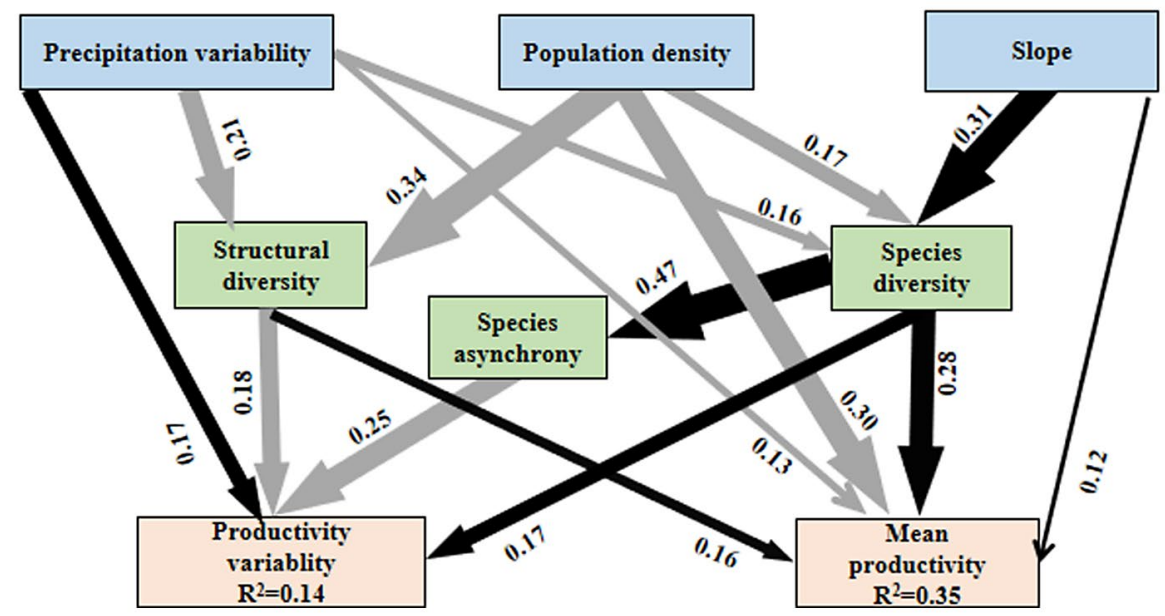

4

\section{DISCUSSION}

\section{1 | Positive effects of tree species diversity on stability in subtropical forests}

Our study provides comprehensive evidence for the importance of tree species richness as a driver of stability in subtropical forests. We found that species richness was significantly and positively correlated with stability, supporting our hypothesis. Many studies have shown that diversity has a positive effect on stability through a combination of processes, such as species asynchrony and species interactions, which were observed in comparatively natural species-poor forests (Aussenac et al., 2019; del Río et al., 2017; Jucker et al., 2014) and in tropical experimental tree plantations (Schnabel et al., 2019). These studies showed that stability was higher in diverse communities compared with species-poor communities. Given the distribution of our dataset, our results of the positive diversity-stability relationship also hold at large spatial extents in high-diversity subtropical forests.

Both species richness and species asynchrony significantly stabilized productivity in subtropical forests, but they influenced the two components of forest stability (mean productivity and its variability) differentially (Figures 2 and 3). Species richness might affect forest stability via an overyielding effect, because diverse communities apparently contain more species that are able to resist changing environmental conditions (Loreau \& Hector, 2001). Species asynchrony could decrease interspecific competition and heterogeneity in response to changing environmental conditions (Loreau \& de Mazancourt, 2013). Our results indicated that species richness increased mean productivity (via an overyielding effect), whereas species asynchrony decreased variability of productivity (Figures 2 and 3). This is consistent with studies based on annual census data in tropical experimental tree plantations (Schnabel et al., 2019) and European temperate forests (Jucker et al., 2014). Interestingly, the 
effect of overyielding was stronger than that of species asynchrony in our study (Table 1; Figures 2 and 3), supporting our second hypothesis. Owing to the longevity of trees and the amount of time they need to build their aboveground biomass (i.e., compared with annual plants), the rate of changes in species composition of forest ecosystems are relatively slow and might be decoupled from variation in interannual climate (Stephenson \& van Mantgem, 2005), implying that forests might manifest weaker effects of species asynchrony than ecosystems composed of shorter-lived species (Jucker et al., 2014). Some previous studies have used annual resolution data to show that tree species asynchrony is a strong driver of stability (Jucker et al., 2014; Schnabel et al., 2019). These different effects of species asynchrony on stability might be attributable to the temporal scales and forest types investigated (Yu et al., 2020). Recent research has provided a useful framework to bridge the stability and synchrony measures across organizational levels and spatial scales (Wang, Lamy, et al., 2019). Based on these results, we suggest that future studies should test the effects of species asynchrony on stability across scales in different natural forest types and at different temporal resolutions.

In addition, our results supported the hypothesis that forests in mountainous areas exhibit higher stability than forests in hilly areas. The coefficient of determination of the relationship between species richness and stability decreased from the forests in mountainous areas to hilly areas, implying that the forests in mountainous areas have more stable productivity through time. This could be explained by differences in topography and the intensity of human activities. Forests in mountainous areas benefit from heterogeneous habitat to foster diverse communities of plant species and experience low human disturbance. In contrast, forests in hilly areas are usually located on gentler topography, with lower elevations and lower slopes; hence, they tend to be more modified by humans. An effect of slope on the association between tree species richness and human activities has been found in other studies (Odgaard et al., 2014).

\subsection{Effects of stand structural and environmental factors on stability}

Stability was influenced simultaneously by stand structure, climate and slope, supporting our third hypothesis. Tree d.b.h. diversity index was positively correlated with mean productivity (Figures 2 and 3), implying that structural diversity was an important determinant for stability in subtropical forests. These relationships might result from increasing light capture or efficiency of light use owing to the complex tree size structures (Forrester, 2019; Forrester et al., 2019).

As expected, climatic variables also had significant effects on forest stability, which is consistent with previous studies (GarcíaPalacios et al., 2018; Pérez-Ramos et al., 2017). Generally, forest productivity at large spatial scales is driven mainly by MAP and MAT (Schuur, 2003; Wu et al., 2015). The positive effect of MAP on stability is attributable to an increase in mean productivity, with no change in productivity variability (Figure 2). The negative effect of precipitation variability on forest stability was explained by its negative effect on mean productivity and positive effect on productivity variability. Precipitation variability might also affect stability indirectly by altering species compositions and diversity (Figures 2 and 3; García-Palacios et al., 2018; Mazzochini et al., 2019). However, we found that temperature and its variability had no significant effects on stability. This might be attributable to the favourable temperature conditions of our study region, with an average annual air temperature of $16-18^{\circ} \mathrm{C}$ (Huang et al., 2014). Moreover, the magnitude of variation in annual air temperature was not large enough to lead to significant changes in forest productivity in our study region (Ouyang et al., 2019). Our results reveal that stability is highly sensitive to fluctuations in rainfall, which mainly affect stability via increasing the variability in productivity. Consequently, species-rich subtropical forests will play a key role in mitigating adverse effects of climate fluctuations and will increase the stability of productivity through time.

Topography also governs geographical gradients in species diversity (Belote, 2018; Nüchel et al., 2019; Wang et al., 2009; Zhang et al., 2019). Slope is a common factor influencing both patterns of land use and species diversity. The strong effect of slope on biodiversity suggests that topography might affect vegetation stability indirectly by influencing species composition and diversity (Belote, 2018). Our results suggest that this indirect effect of slope occurs mainly by modulating plant species richness and thereby has an indirect effect on stability. This analysis illustrates that the correlation often found between site conditions and ecosystem stability might be attributable, in part, to an indirect relationship reflecting changes in plant diversity (Nüchel et al., 2019; Zhang et al., 2019). Not surprisingly, slope steepness was also related to human modification (Nüchel et al., 2019). Regions with steeper slopes were less impacted by human modification. Similar patterns are observed globally, where the human footprint tends to be lower in areas characterized by steeper slopes (Belote, 2018; Nüchel et al., 2019). Forests with steeper slopes are more difficult and costly to harvest and, therefore, represent lands more easily set aside in reserves (Nüchel et al., 2019). Areas at higher elevations and with steeper slopes are also less attractive and less accessible for humans or large herbivores and, therefore, act as refuges for forests (Bakker et al., 2016; Nüchel et al., 2019).

\section{3 | Socio-economic factors important in determining stability}

Humans use forests by extracting timber, food and fuel and by building the transportation and infrastructure in order to support our social and economic systems [Costanza et al., 2014; FAO, 2015]. Pressures from these human activities have caused forest fragmentation and degradation [Chazdon et al., 2017; Ferreira et al., 2018; FAO, 2015]. Consequently, these processes could be undermining stability and the capacity to maintain core ecosystem services (Chen et al., 2018; Steffen et al., 2015; Venter et al., 2016). 
We found that socio-economic activities (e.g., population density) had negative effects on stability, which is in line with findings from previous studies (McKinney, 2006; Wen et al., 2017; Zhou et al., 2015). For instance, Wen et al. (2017) found that anthropogenic activity (e.g., higher population density and percentage of urbanization) negatively affected forest vegetation growth owing to the higher risk of destruction of vegetation. Nüchel et al. (2019) also showed that the there was an increase in tree growth in eastern China owing to low and declining human pressure. Furthermore, there is mounting evidence that human demands on these natural systems are accelerating and have resulted in adverse effects on natural ecosystems (e.g., loss of forest biodiversity and increases in greenhouse gas emissions) (Chen et al., 2018; Martínez-Ramos et al., 2016; Steffen et al., 2015; Venter et al., 2016). We also found that socio-economic activities could significantly and negatively affect tree species diversity and ultimately have a significant influence on stability.

In general, the forests distributed at low elevations and on flat or minor slopes indicate relatively more human disturbance owing to high accessibility and more intensive socio-economic activities (Belote, 2018). In contrast, the forests characterized as being much less accessible always have high naturalness and more biodiversity. The difference in topography is, therefore, the dominant factor affecting human activities, forest quality and their relevant relationships. The difference in the main drivers of stability in forests between hilly and mountainous areas could also be explained by the different intensity of human activities. During the 2000-2015 period, because of higher human population density and urbanization, forests in hilly areas were usually associated with higher demand for forest natural resources (e.g., food, fibre and fuel) for developed lands and transportation infrastructure compared with forests in mountainous areas. In contrast, many mountainous areas that have experienced a decline in population density and an increase in tree cover (a proxy for productivity) appeared in the areas with marginal farmlands abandoned in recent years, in particular, in mountainous areas with steep slopes, attributable to rural-to-urban migration in China (Nüchel et al., 2019; Nüchel \& Svenning, 2017).

\section{4 | Implications and limitations}

We have attempted to provide one of the first comprehensive analyses of how diversity, stand structure, socio-economic and environmental factors shape the stability of subtropical forests. The results provide valuable information for policy-makers and practice at national and regional levels and highlight the importance of the conservation of diverse forests for maintaining and enhancing their stability in terms of providing the key ecosystem services in an increasingly uncertain future. However, our work is subject to two main limitations.

The first limitation of our results is the fact that temporal stability was examined based on the estimate of productivity calculated from 5-year measurement intervals rather than on an annual basis. This might underestimate or mask any year-to-year effects of climate variability. However, annual measurement intervals are rare for inventories that cover large areas, leading to a trade-off between high temporal resolution (annual measurement intervals), high spatial coverage representative of whole regions and highly diverse species compositions. The productivity-diversity relationships were dominated by the woody part of vegetation (Brun et al., 2019). Given that trees are long lived and there was no regeneration of the annual aboveground biomass each year (Stephenson \& van Mantgem, 2005), changes in the species composition of forests are relatively slow compared with grassland ecosystems (Jucker et al., 2014). It has, therefore, been suggested that the stability-diversity relationships of forests might be less affected by interannual variations in climate in the short term. Moreover, the 5-year-resolution national forest inventory data used in this study have been used successfully to derive large-scale estimates of productivity (Fang et al., 2014; Pan et al., 2011) and have provided important insights into biodiversity-productivity relationships in forest ecosystems at large scales (Guo et al., 2014; Ouyang et al., 2019; Wu et al., 2015). Another study (Yuan et al., 2019), which used three repeated inventories of 5-year inventory data to examine the relationship between species asynchrony and stability in temperate Chinese forests, recommended that at least four repeated inventories should be used to analyse the stability of productivity, as done in the present study.

The second limitation of our study is that the contributions of the understorey species to productivity and stability were not considered. It is worth mentioning that the ecosystem services provided by the forests should reflect the contributions of all species in different layers, not only the tree layer, although the main focus of forestry is often timber production (Guo \& Ren, 2014; Lugo, 1997). Thus, investigation of the contributions of both over- and understorey plants would help to provide a more accurate and complete understanding of the functioning and overall performance of forest ecosystems in future changing environmental conditions.

\section{5 | Conclusions}

We demonstrated that species diversity exerted a positive effect on stability, and this effect was stronger in the forests in mountainous areas than that in hilly areas. Our study also showed that species richness increased mean tree productivity and that species asynchrony decreased the variation in productivity, which in turn enhanced community stability. Socio-economic and environmental conditions also influenced stability directly and indirectly via their effects on diversity and stand structure in subtropical forests. Our results indicated that forests in mountainous areas, mainly with a lower intensity of human disturbance (e.g., low or declining population density) and steep topography, were more likely to experience higher stability. Therefore, we argue that future studies focusing on the effect of diversity on key ecosystem 
functions could benefit from examining how socio-economic factors influence the relationship between diversity and ecosystem functioning along topographic gradients at regional scales. These results could provide valuable information for policy-making and to improve forest management and conservation initiatives in the face of future changing environmental and socio-economic conditions.

\section{ACKNOWLEDGMENTS}

This work was supported by the National Key Research and Development Program of China (2016YFD0600202), National Natural Science Foundation of China (31700636), China Postdoctoral Science Foundation (2017M612605), Research Foundation of Education Bureau of Hunan Province (19B586) and Huitong Forest Ecological Station Program funded by the State Forestry and Grassland Administration of China (2020132080). We thank Dr Xiangcheng $\mathrm{Mi}$, from the Institute of Botany, Chinese Academy of Science, for the insightful comments.

\section{CONFLICT OF INTERESTS}

The authors declare there is no conflict of interest in relationship to this study.

\section{AUTHOR CONTRIBUTIONS}

S.O. and W. Xiang designed the research; W. Xiang, M.G., W. Xiao, L.Z., T.Z., D.I.F. and C.P. conceived ideas; S.O., M.G., L.C., X.D., J.L. and P.L. compiled and analysed the data; S.O. and W. Xiang led the writing of the manuscript. All authors revised the manuscript and gave final approval for publication.

\section{DATA AVAILABILITY STATEMENT}

All of the data used for analysis in this study are clearly documented in the Materials and Methods section and in Table 1. All data used for analysis are available from the Dryad Digital Repository https://doi.org/10.5061/dryad.zcrjdfn93 (Ouyang et al., 2020).

\section{ORCID}

Shuai Ouyang (iD https://orcid.org/0000-0002-2965-1929

Wenhua Xiang (iD https://orcid.org/0000-0002-6762-7938

Tao Zhang (iD https://orcid.org/0000-0001-7135-1762

\section{REFERENCES}

Aussenac, R., Bergeron, Y., Gravel, D., \& Drobyshev, I. (2019). Interactions among trees: A key element in the stabilising effect of species diversity on forest growth. Functional Ecology, 33, 360-367. https://doi. org/10.1111/1365-2435.13257

Bakker, E. S., Gill, J. L., Johnson, C. N., Vera, F. W., Sandom, C. J., Asner, G. P., \& Svenning, J. C. (2016). Combining paleo-data and modern exclosure experiments to assess the impact of megafauna extinctions on woody vegetation. Proceedings of the National Academy of Sciences USA, 113, 847-855. https://doi.org/10.1073/pnas.1502545112

Bartoń, K. (2016). MuMIn: Multi-Model Inference. R package version 1.15.6. https://CRAN.R-project.org/package=MuMIn
Belote, R. T. (2018). Species-rich national forests experience more intense human modification, but Why? Forests, 9, 753. https://doi. org/10.3390/f9120753

Bohlman, S. A., Laurance, W. F., Laurance, S. G., Nascimento, H. E., Fearnside, P. M., \& Andrade, A. (2008). Importance of soils, topography and geographic distance in structuring central Amazonian tree communities. Journal of Vegetation Science, 19, 863-874. https://doi. org/10.3170/2008-8-18463

Brun, P., Zimmermann, N. E., Graham, C. H., Lavergne, S., Pellissier, L., Münkemüller, T., \& Thuiller, W. (2019). The productivity-biodiversity relationship varies across diversity dimensions. Nature Communications, 10, 5691. https://doi.org/10.1038/s41467-01913678-1

Burnham, K. P., \& Anderson, D. R. (2002). Model selection and multimodel inference: A practical information-theoretic approach. Springer.

Chazdon, R. L., Brancalion, P. H., Lamb, D., Laestadius, L., Calmon, M., \& Kumar, C. (2017). A policy-driven knowledge agenda for global forest and landscape restoration. Conservation Letters, 10, 125-132. https://doi.org/10.1111/conl.12220

Chen, S., Wang, W., Xu, W., Wang, Y., Wan, H., Chen, D., Tang, Z., Tang, X., Zhou, G., Xie, Z., Zhou, D., Shangguan, Z., Huang, J., He, J.-S., Wang, Y., Sheng, J., Tang, L., Li, X., Dong, M., ... Bai, Y. (2018). Plant diversity enhances productivity and soil carbon storage. Proceedings of the National Academy of Sciences USA, 115, 4027-4032. https:// doi.org/10.1073/pnas.1700298114

Costanza, R., de Groot, R., Sutton, P., van der Ploeg, S., Anderson, S. J., Kubiszewski, I., Farber, S., \& Turner, R. K. (2014). Changes in the global value of ecosystem services. Global Environmental Change, 26, 152-158. https://doi.org/10.1016/j.gloenvcha.2014.04.002

Craven, D., Eisenhauer, N., Pearse, W. D., Hautier, Y., Isbell, F., Roscher, C., Bahn, M., Beierkuhnlein, C., Bönisch, G., Buchmann, N., Byun, C., Catford, J. A., Cerabolini, B. E. L., Cornelissen, J. H. C., Craine, J. M., De Luca, E., Ebeling, A., Griffin, J. N., Hector, A., ... Manning, P. (2018). Multiple facets of biodiversity drive the diversity-stability relationship. Nature Ecology \& Evolution, 2, 1579-1587. https://doi. org/10.1038/s41559-018-0647-7

Dănescu, A., Albrecht, A. T., \& Bauhus, J. (2016). Structural diversity promotes productivity of mixed, uneven-aged forests in southwestern Germany. Oecologia, 182, 319-333. https://doi.org/10.1007/s0044 2-016-3623-4

del Río, M., Pretzsch, H., Ruíz-Peinado, R., Ampoorter, E., Annighöfer, P., Barbeito, I., \& Fabrika, M. (2017). Species interactions increase the temporal stability of community productivity in Pinus sylvestris-Fagus sylvatica mixtures across Europe. Journal of Ecology, 105, 1032-1043.

Fang, J., Guo, Z., Hu, H., Kato, T., Muraoka, H., \& Son, Y. (2014). Forest biomass carbon sinks in east Asia, with special reference to the relative contributions of forest expansion and forest growth. Global Change Biology, 20, 2019-2030. https://doi.org/10.1111/gcb.12512

Ferreira, J., Lennox, G. D., Gardner, T. A., Thomson, J. R., Berenguer, E., Lees, A. C., Mac Nally, R., Aragão, L. E. O. C., Ferraz, S. F. B., Louzada, J., Moura, N. G., Oliveira, V. H. F., Pardini, R., Solar, R. R. C., Vieira, I. C. G., \& Barlow, J. (2018). Carbon-focused conservation may fail to protect the most biodiverse tropical forests. Nature Climate Change, 8, 744-749. https://doi.org/10.1038/s41558-018-0225-7

Food and Agriculture Organization (FAO). (2015). Global forest resources assessment, Rome: FAO.

Forrester, D. I. (2019). Linking forest growth with stand structure: Tree size inequality, tree growth or resource partitioning and the asymmetry of competition. Forest Ecology and Management, 447, 139-157. https://doi.org/10.1016/j.foreco.2019.05.053

Forrester, D. I., Rodenfels, P., Haase, J., Härdtle, W., Leppert, K. N., Niklaus, P. A., von Oheimb, G., Scherer-Lorenzen, M., \& Bauhus, J. (2019). Tree-species interactions increase light absorption and 
growth in Chinese subtropical mixed-species plantations. Oecologia, 191, 421-432. https://doi.org/10.1007/s00442-019-04495-w

Fox, J., Weisberg, S., Adler, D., Bates, D., Baud-Bovy, G., Ellison, S., \& Heiberger, R. (2017). Package 'car'. R Foundation for Statistical Computing.

García-Palacios, P., Gross, N., Gaitán, J., \& Maestre, F. T. (2018). Climate mediates the biodiversity-ecosystem stability relationship globally. Proceedings of the National Academy of Sciences USA, 115, 84008405. https://doi.org/10.1073/pnas.1800425115

Gonzalez, A., Germain, R. M., Srivastava, D. S., Filotas, E., Dee, L. E., Gravel, D., Thompson, P. L., Isbell, F., Wang, S., Kéfi, S., Montoya, J., Zelnik, Y. R., \& Loreau, M. (2020). Scaling-up biodiversity-ecosystem functioning research. Ecology Letters, 23, 757-776. https://doi. org/10.1111/ele.13456

Grace, J. B., Anderson, T. M., Seabloom, E. W., Borer, E. T., Adler, P. B., Harpole, W. S., Hautier, Y., Hillebrand, H., Lind, E. M., Pärtel, M., Bakker, J. D., Buckley, Y. M., Crawley, M. J., Damschen, E. I., Davies, K. F., Fay, P. A., Firn, J., Gruner, D. S., Hector, A., ... Smith, M. D. (2016). Integrative modelling reveals mechanisms linking productivity and plant species richness. Nature, 529, 390-393. https://doi. org/10.1038/nature16524

Greve, M., Lykke, A. M., Blach-Overgaard, A., \& Svenning, J. C. (2011). Environmental and anthropogenic determinants of vegetation distribution across Africa. Global Ecology and Biogeography, 20, 661-674. https://doi.org/10.1111/j.1466-8238.2011.00666.x

Guo, Q., \& Ren, H. (2014). Productivity as related to diversity and age in planted versus natural forests. Global Ecology and Biogeography, 23 1461-1471. https://doi.org/10.1111/geb.12238

Guo, Y., Wang, B., Mallik, A. U., Huang, F., Xiang, W., Ding, T., \& Li, X. (2017). Topographic species-habitat associations of tree species in a heterogeneous tropical karst seasonal rain forest, China. Journal of Plant Ecology, 10, 450-460.

Hautier, Y., Seabloom, E. W., Borer, E. T., Adler, P. B., Harpole, W. S., Hillebrand, H., Lind, E. M., MacDougall, A. S., Stevens, C. J., Bakker J. D., Buckley, Y. M., Chu, C., Collins, S. L., Daleo, P., Damschen, E. I., Davies, K. F., Fay, P. A., Firn, J., Gruner, D. S., ... Hector, A. (2014). Eutrophication weakens stabilizing effects of diversity in natural grasslands. Nature, 508, 521-525. https://doi.org/10.1038/natur e13014

Hector, A., Hautier, Y., Saner, P., Wacker, L., Bagchi, R., Joshi, J., SchererLorenzen, M., Spehn, E. M., Bazeley-White, E., Weilenmann, M. Caldeira, M. C., Dimitrakopoulos, P. G., Finn, J. A., Huss-Danell, K., Jumpponen, A., Mulder, C. P. H., Palmborg, C., Pereira, J. S., Siamantziouras, A. S. D., ... Loreau, M. (2010). General stabilizing effects of plant diversity on grassland productivity through population asynchrony and overyielding. Ecology, 9, 2213-2220. https://doi. org/10.1890/09-1162.1

Hutchison, J., Manica, A., Swetnam, R., Balmford, A., \& Spalding, M (2014). Predicting global patterns in mangrove forest biomass. Conservation Letters, 7, 233-240.

Holmgren, M., Hirota, M., Van Nes, E. H., \& Scheffer, M. (2013). Effects of interannual climate variability on tropical tree cover. Nature Climate Change, 3, 755-758. https://doi.org/10.1038/nclim ate1906

Huang, J., Sun, S., Xue, Y., \& Zhang, J. (2014). Spatial and temporal variability of precipitation indices during 1961-2010 in Hunan Province, central south China. Theoretical and Applied Climatology, 118, 581595. https://doi.org/10.1007/s00704-013-1087-6

Huang, Y., Fu, J., Wang, W., \& Li, J. (2019). Development of China's nature reserves over the past 60 years: An overview. Land Use Policy, 80, 224-232. https://doi.org/10.1016/j.landusepol.2018.10.020

Isbell, F., Craven, D., Connolly, J., Loreau, M., Schmid, B., Beierkuhnlein, C., Bezemer, T. M., Bonin, C., Bruelheide, H., de Luca, E., Ebeling, A., Griffin, J. N., Guo, Q., Hautier, Y., Hector, A., Jentsch, A., Kreyling, J., Lanta, V., Manning, P., ... Eisenhauer, N. (2015). Biodiversity increases the resistance of ecosystem productivity to climate extremes. Nature, 526, 524-577. https://doi.org/10.1038/nature15374

Isbell, F., Gonzalez, A., Loreau, M., Cowles, J., Díaz, S., Hector, A., Mace, G. M., Wardle, D. A., O'Connor, M. I., Duffy, J. E., Turnbull, L. A., Thompson, P. L., \& Larigauderie, A. (2017). Linking the influence and dependence of people on biodiversity across scales. Nature, 546, 65-72. https://doi.org/10.1038/nature22899

Jactel, H., Bauhus, J., Boberg, J., Bonal, D., Castagneyrol, B., Gardiner, B., \& Brockerhoff, E. G. (2017). Tree diversity drives forest stand resistance to natural disturbances. Current Forestry Reports, 33, 223-243.

Jucker, T., Avăcăriței, D., Bărnoaiea, I., Duduman, G., Bouriaud, O., \& Coomes, D. A. (2016). Climate modulates the effects of tree diversity on forest productivity. Journal of Ecology, 104, 388-398. https://doi. org/10.1111/1365-2745.12522

Jucker, T., Bouriaud, O., Avacaritei, D., \& Coomes, D. A. (2014). Stabilizing effects of diversity on aboveground wood production in forest ecosystems: Linking patterns and processes. Ecology Letters, 17, 15601569. https://doi.org/10.1111/ele.12382

Lehman, C. L., \& Tilman, D. (2000). Biodiversity, stability, and productivity in competitive communities. The American Naturalist, 156, 534552. https://doi.org/10.1086/303402

Lei, X., Wang, W., \& Peng, C. (2009). Relationships between stand growth and structural diversity in spruce-dominated forests in $\mathrm{New}$ Brunswick, Canada. Canadian Journal of Forest Research, 39, 18351847. https://doi.org/10.1139/X09-089

Liang, J., Buongiorno, J., Monserud, R. A., Kruger, E. L., \& Zhou, M. (2007). Effects of diversity of tree species and size on forest basal area growth, recruitment, and mortality. Forest Ecology and Management, 243, 116-127. https://doi.org/10.1016/j.foreco.2007.02.028

Liu, X., Trogisch, S., He, J., Niklaus, P. A., Bruelheide, H., Tang, Z., \& Ma, K. (2018). Tree species richness increases ecosystem carbon storage in subtropical forests. Proceedings of the Royal Society B: Biological Sciences, 285, 20181240

Loreau, M., \& de Mazancourt, C. (2013). Biodiversity and ecosystem stability: A synthesis of underlying mechanisms. Ecology Letters, 16, 106-115. https://doi.org/10.1111/ele.12073

Loreau, M., \& Hector, A. (2001). Partitioning selection and complementarity in biodiversity experiments. Nature, 412, 72-76. https://doi. org $/ 10.1038 / 35083573$

Lugo, A. E. (1997). The apparent paradox of reestablishing species richness on degraded lands with tree monocultures. Forest Ecology and Management, 99, 9-19. https://doi.org/10.1016/S0378 -1127(97)00191-6

Martínez-Ramos, M., Ortiz-Rodríguez, I. A., Piñero, D., Dirzo, R., \& Sarukhán, J. (2016). Anthropogenic disturbances jeopardize biodiversity conservation within tropical rainforest reserves. Proceedings of the National Academy of Sciences USA, 113, 5323-5328. https://doi. org/10.1073/pnas.1602893113

Mazzochini, G. G., Fonseca, C. R., Costa, G. C., Santos, R. M., OliveiraFilho, A. T., \& Ganade, G. (2019). Plant phylogenetic diversity stabilizes large-scale ecosystem productivity. Global Ecology and Biogeography, 28, 1430-1439. https://doi.org/10.1111/geb.12963

McKinney, M. L. (2006). Urbanization as a major cause of biotic homogenization. Biological Conservation, 127, 247-260. https://doi. org/10.1016/j.biocon.2005.09.005

Messier, C., Bauhus, J., Doyon, F., Maure, F., Sousa-Silva, R., Nolet, P., Mina, M., Aquilué, N., Fortin, M.-J., \& Puettmann, K. (2019). The functional complex network approach to foster forest resilience to global changes. Forest Ecosystems, 6, 21. https://doi.org/10.1186/ s40663-019-0166-2

Millar, C. I., \& Stephenson, N. L. (2015). Temperate forest health in an era of emerging megadisturbance. Science, 349, 823-826. https://doi. org/10.1126/science.aaa9933

Newbold, T., Hudson, L. N., Hill, S. L. L., Contu, S., Lysenko, I., Senior, R. A., Börger, L., Bennett, D. J., Choimes, A., Collen, B., Day, J., De 
Palma, A., Díaz, S., Echeverria-Londoño, S., Edgar, M. J., Feldman, A., Garon, M., Harrison, M. L. K., Alhusseini, T., ... Purvis, A. (2015). Global effects of land use on local terrestrial biodiversity. Nature, 520, 45-50. https://doi.org/10.1038/nature14324

Nüchel, J., Bøcher, P. K., \& Svenning, J. C. (2019). Topographic slope steepness and anthropogenic pressure interact to shape the distribution of tree cover in China. Applied Geography, 103, 40-55. https:// doi.org/10.1016/j.apgeog.2018.12.008

Nüchel, J., \& Svenning, J. C. (2017). Recent tree cover increases in eastern China linked to low, declining human pressure, steep topography, and climatic conditions favoring tree growth. PLoS One, 12, e0177552. https://doi.org/10.1371/journal.pone.0177552

Odgaard, M. V., Bøcher, P. K., Dalgaard, T., Moeslund, J. E., \& Svenning, J. C. (2014). Human-driven topographic effects on the distribution of forest in a flat, lowland agricultural region. Journal of Geographical Sciences, 24, 76-92. https://doi.org/10.1007/s1144 2-014-1074-6

Ouyang, S., Xiang, W., Gou, M., Chen, L., Lei, P., Xiao, W., Deng, X., Zeng, L., Li, J., Zhange, T., Peng, C., \& Forrester, D. I. (2020). Stability in subtropical forests: The role of tree-species diversity, stand structure, environmental and socio-economic conditions. Dryad Dataset. https://doi.org/10.5061/dryad.zcrjdfn93

Ouyang, S., Xiang, W., Wang, X., Xiao, W., Chen, L., Li, S., Sun, H., Deng, X., Forrester, D. I., Zeng, L., Lei, P., Lei, X., Gou, M., \& Peng, C. (2019). Effects of stand age, richness and density on productivity in subtropical forests in China. Journal of Ecology, 107, 2266-2277. https://doi. org/10.1111/1365-2745.13194

Pan, Y., Birdsey, R. A., Fang, J., Houghton, R., Kauppi, P. E., Kurz, W. A., Phillips, O. L., Shvidenko, A., Lewis, S. L., Canadell, J. G., Ciais, P., Jackson, R. B., Pacala, S. W., McGuire, A. D., Piao, S., Rautiainen, A., Sitch, S., \& Hayes, D. (2011). A large and persistent carbon sink in the world's forests. Science, 333, 988-993. https://doi.org/10.1126/ science.1201609

Pérez-Ramos, I. M., Díaz-Delgado, R., de la Riva, E. G., Villar, R., Lloret, F., \& Marañón, T. (2017). Climate variability and community stability in Mediterranean shrublands: The role of functional diversity and soil environment. Journal of Ecology, 105, 1335-1346. https://doi. org/10.1111/1365-2745.12747

Polley, H. W., \& Wilsey, B. J. (2018). Variability in community productivity-mediating effects of vegetation attributes. Functional Ecology, 32, 1410-1419. https://doi.org/10.1111/1365-2435.13080

Poorter, L., van der Sande, M. T., Arets, E. J. M. M., Ascarrunz, N., Enquist, B. J., Finegan, B., Licona, J. C., Martínez-Ramos, M., Mazzei, L., Meave, J. A., Muñoz, R., Nytch, C. J., de Oliveira, A. A., PérezGarcía, E. A., Prado-Junior, J., Rodríguez-Velázques, J., Ruschel, A. R., Salgado-Negret, B., Schiavini, I., ... Peña-Claros, M. (2017). Biodiversity and climate determine the functioning of Neotropical forests. Global Ecology and Biogeography, 26, 1423-1434. https://doi. org/10.1111/geb.12668

Qi, C. J. (1990). Hunan vegetation [in Chinese]. Hunan Science and Technology Press.

Quan, J., Ouyang, Z., Xu, W., \& Miao, H. (2011). Assessment of the effectiveness of nature reserve management in China. Biodiversity and Conservation, 20, 779-792. https://doi.org/10.1007/s1053 1-010-9978-7

R Core Team. (2019). R: A language and environment for statistical computing. R Foundation for Statistical Computing. https://www.R-proje ct.org/

Rosseel, Y. (2012). lavaan: An R package for structural equation modeling. Journal of Statistical Software, 48, 1-36.

Schnabel, F., Schwarz, J. A., Dănescu, A., Fichtner, A., Nock, C. A., Bauhus, J., \& Potvin, C. (2019). Drivers of productivity and its temporal stability in a tropical tree diversity experiment. Global Change Biology, 25, 4257-4272. https://doi.org/10.1111/gcb.14792
Schulze, E. D., Bouriaud, O., Weber, U., Roscher, C., Hessenmoeller, D., Kroiher, F., \& Schall, P. (2018). Management breaks the natural productivity-biodiversity relationship in forests and grassland: An opinion. Forest Ecosystems, 5, 3. https://doi.org/10.1186/s4066 3-017-0122-y

Schuur, E. A. G. (2003). Productivity and global climate revisited: The sensitivity of tropical forest growth to precipitation. Ecology, 84, 1165-1170. https://doi.org/10.1890/0012-9658(2003)084[1165 :PAGCRT]2.0.CO;2

Soares, A. A. V., Leite, H. G., Souza, A. L., Silva, S. R., Lourenço, H. M., \& Forrester, D. I. (2016). Increasing stand structural heterogeneity reduces productivity in Brazilian Eucalyptus monoclonal stands. Forest Ecology and Management, 373, 26-32. https://doi.org/10.1016/j. foreco.2016.04.035

Song, Y. C. (2013). Evergreen broadleaved forest in China: Classification, ecology and conservation [In Chinese]. Chinese Science Press.

Steffen, W., Broadgate, W., Deutsch, L., Gaffney, O., \& Ludwig, C. (2015). The trajectory of the Anthropocene: The great acceleration. The Anthropocene Review, 2, 81-98. https://doi.org/10.1177/20530 19614564785

Stephenson, N. L., \& van Mantgem, P. J. (2005). Forest turnover rates follow global and regional patterns of productivity. Ecology Letters, 8 , 524-531. https://doi.org/10.1111/j.1461-0248.2005.00746.x

Takyu, M., Aiba, S. I., \& Kitayama, K. (2002). Effects of topography on tropical lower montane forests under different geological conditions on Mount Kinabalu, Borneo. Plant Ecology, 159, 35-49.

Uriarte, M., Pinedo-Vasquez, M., DeFries, R. S., Fernandes, K., GutierrezVelez, V., Baethgen, W. E., \& Padoch, C. (2012). Depopulation of rural landscapes exacerbates fire activity in the western Amazon. Proceedings of the National Academy of Sciences USA, 109, 2154621550. https://doi.org/10.1073/pnas.1215567110

van der Plas, F., Manning, P., Soliveres, S., Allan, E., Scherer-Lorenzen, M., Verheyen, K., Wirth, C., Zavala, M. A., Ampoorter, E., Baeten, L., Barbaro, L., Bauhus, J., Benavides, R., Benneter, A., Bonal, D., Bouriaud, O., Bruelheide, H., Bussotti, F., Carnol, M., ... Fischer, M. (2016). Biotic homogenization can decrease landscape-scale forest multifunctionality. Proceedings of the National Academy of Sciences USA, 113, 3557-3562. https://doi.org/10.1073/ pnas.1517903113

Venter, O., Sanderson, E. W., Magrach, A., Allan, J. R., Beher, J., Jones, K. R., Possingham, H. P., Laurance, W. F., Wood, P., Fekete, B. M., Levy, M. A., \& Watson, J. E. M. (2016). Sixteen years of change in the global terrestrial human footprint and implications for biodiversity conservation. Nature Communications, 7, 12558. https://doi.org/10.1038/ ncomms 12558

Wang, S., Lamy, T., Hallett, L. M., \& Loreau, M. (2019). Stability and synchrony across ecological hierarchies in heterogeneous metacommunities: Linking theory to data. Ecography, 42, 1200-1211. https://doi. org/10.1111/ecog.04290

Wang, S., \& Loreau, M. (2016). Biodiversity and ecosystem stability across scales in metacommunities. Ecology Letters, 19, 510-518. https://doi.org/10.1111/ele.12582

Wang, Y., Cadotte, M. W., Chen, Y., Fraser, L. H., Zhang, Y., Huang, F., Luo, S., Shi, N., \& Loreau, M. (2019). Global evidence of positive biodiversity effects on spatial ecosystem stability in natural grasslands. Nature Communications, 10, 3207. https://doi.org/10.1038/s4146 7-019-11191-z

Wang, Z., Ye, W., Cao, H., Huang, Z., Lian, J., Li, L., Wei, S., \& Sun, I.-F. (2009). Species-topography association in a species-rich subtropical forest of China. Basic and Applied Ecology, 10, 648-655. https://doi. org/10.1016/j.baae.2009.03.002

Warton, D. I., Duursma, R. A., Falster, D. S., \& Taskinen, S. (2012). SMART 3-an R package for estimation and inference about allometric lines. Methods in Ecology and Evolution, 3, 257-259. 
Weiner, J., \& Solbrig, O. T. (1984). The meaning and measurement of size hierarchies in plant populations. Oecologia, 61, 334-336. https://doi. org/10.1007/BF00379630

Wen, Z., Wu, S., Chen, J., \& Lü, M. (2017). NDVI indicated long-term interannual changes in vegetation activities and their responses to climatic and anthropogenic factors in the Three Gorges Reservoir Region, China. Science of the Total Environment, 574, 947-959. https:// doi.org/10.1016/j.scitotenv.2016.09.049

Wu, X., Wang, X., Tang, Z., Shen, Z., Zheng, C., Xia, X., \& Fang, J. (2015) The relationship between species richness and biomass changes from boreal to subtropical forests in China. Ecography, 37, 602v613. https://doi.org/10.1111/ecog.00940

Xiang, W., Zhou, J., Ouyang, S., Zhang, S., Lei, P., Li, J., \& Forrester, D. I. (2016). Species-specific and general allometric equations for estimating tree biomass components of subtropical forests in southern China. European Journal of Forest Research, 135, 963-979.

Xu, X. (2017a). China population spatial distribution kilometer grid dataset, Resource and Environment Data Cloud Platform, Beijing, China. https://doi.org/10.12078/2017121101

Xu, X. (2017b). China GDP spatial distribution kilometer grid dataset Resource and Environment Data Cloud Platform, Beijing, China. https://doi.org/10.12078/2017121102

Yu, Q., Rao, X., Chu, C., Liu, S., Lin, Y., Sun, D., \& Shen, W. (2020). Species dominance rather than species asynchrony determines the temporal stability of productivity in four subtropical forests along 30 years of restoration. Forest Ecology and Management, 457, 117687.

Yuan, Z., Ali, A., Wang, S., Wang, X., Lin, F., Wang, Y., \& Jiang, L. (2019). Temporal stability of aboveground biomass is governed by species asynchrony in temperate forests. Ecological Indicators, 107, 105661.

Zhang, X., Zhang, B., Feeley, K. J., Wang, G. G., Zhang, J., \& Zhai, L. (2019). Ecological contingency in species shifts: Downslope shifts of woody species under warming climate and land-use change. Environmental Research Letters, 14, 114033.

Zhang, Y., \& Chen, H. Y. (2015). Individual size inequality links forest diversity and above-ground biomass. Journal of Ecology, 103, 1245-1252.
Zhao, M., \& Running, S. W. (2010). Drought-induced reduction in global terrestrial net primary production from 2000 through 2009. Science, 329, 940-943.

Zhou, Y., Zhang, L., Fensholt, R., Wang, K., Vitkovskaya, I., \& Tian, F. (2015). Climate contributions to vegetation variations in central Asian drylands: Pre-and post-USSR collapse. Remote Sensing, 7, 2449-2470.

\section{BIOSKETCH}

The author team is broadly interested in understanding the relationship between biodiversity and ecosystem functioning in forest ecosystems. The authors have specific expertise in community ecology, functional ecology, biogeography and environmental sciences.

\section{SUPPORTING INFORMATION}

Additional supporting information may be found online in the Supporting Information section.

How to cite this article: Ouyang S, Xiang W, Gou M, et al. Stability in subtropical forests: The role of tree species diversity, stand structure, environmental and socio-economic conditions. Global Ecol Biogeogr. 2021;30:500-513. https://doi.org/10.1111/geb.13235 